\title{
A IMPORTÂNCIA DA EDUCAÇÃO AMBIENTAL NO COTIDIANO ESCOLAR
}

\author{
Lucyelen Costa Amorim ${ }^{1}$ \\ Mayara Cazadini Carlos ${ }^{2}$ \\ Adriana de Medeiros Marcolano Thebas ${ }^{3}$
}

Resumo: O trabalho teve por objetivo a busca de informações sobre como a educação ambiental tem sido trabalhada nas escolas e ainda salientar sua importância no cotidiano escolar para que o aluno tenha uma visão mais preocupante sobre os problemas relacionados ao meio ambiente. A pesquisa foi realizada por meio de questionários aplicado aos alunos do ensino regular de $5^{a}$ a $8^{a}$ série de uma escola estadual do município de Alegre ES. Dos alunos entrevistados 73\% responderam não ter realizado junto com o professor nenhum trabalho extraclasse relacionado a Educação Ambiental ou ter saído com o professor para ver os problemas ambientais causados pelo homem. Os alunos sabem teoricamente o que é, e da importância quando se fala de educação ambiental, entretanto, não percebem na prática a importância de cuidar do meio ambiente em que vivem. A educação ambiental não deve ser voltada apenas a transmissão de conhecimentos a respeito do planeta e o meio em que vivemos, mas possibilitar o coletivo, a participação social no sentido de cuidar do que é de todos, para que dessa forma possamos viver em um planeta mais sustentável.

Palavras-chave: Ambiente; Educação; Escola.

\footnotetext{
${ }^{1}$ Ciências Biológicas/Instituto Federal do Espírito Santo - Campus Alegre, Brasil. E-mail: lucyelen_amorim@hotmail.com.br.

2 Ciências Biológicas/Instituto Federal do Espírito Santo - Campus Alegre, Brasil. E-mail: may_cazadini@hotmail.com.

${ }^{3}$ Letras/Faculdade de Filosofia Ciências e Letras de Alegre, Brasil. E-mail: marcolano20@hotmail.com.
} 